\title{
Influence of body mass index on the efficacy of revascularization in patients with coronary artery disease
}

\author{
Aslan T. Turer, MD, ${ }^{a}$ Kenneth W. Mahaffey, MD, ${ }^{\mathrm{a}, \mathrm{b}}$ Emily Honeycutt, MBI, ${ }^{\mathrm{b}}$ Robert H. Tuttle, MSPH, ${ }^{\mathrm{b}}$ Linda K. Shaw, MS, ${ }^{\mathrm{b}}$ \\ Michael H. Sketch, Jr, MD, ${ }^{\text {a }}$ Peter K. Smith, MD, ${ }^{\mathrm{c}}$ Robert M. Califf, MD, ${ }^{\mathrm{a}}$ and John H. Alexander, MD, MHS ${ }^{\mathrm{a}, \mathrm{b}}$
} Objective: We examined the effect of body mass index on the association between revascularization strategy and
survival in patients with coronary artery disease.

\begin{abstract}
Methods: Using the Duke Database for Cardiovascular Disease, we selected 22,877 patients who underwent cardiac catheterization from January 1986 to August 2004 and were found to have significant coronary artery disease. Patients were categorized into three coronary disease management groups: no revascularization, percutaneous coronary intervention, and coronary artery bypass surgery. Propensity scoring was used to control for coronary artery revascularization strategy. The relationship between body mass index, coronary disease treatment, and survival was assessed via Cox multivariable models adjusting for baseline demographic, clinical, and angiographic characteristics.

Results: The median body mass index was $27.2 \mathrm{~kg} / \mathrm{m}^{2}(24.4-30.4)$ in the overall cohort, $27.1 \mathrm{~kg} / \mathrm{m}^{2}(24.1-30.3)$ in the no revacularization group, $27.4 \mathrm{~kg} / \mathrm{m}^{2}(24.8-30.9)$ in the percutaneous intervention group, and $26.9 \mathrm{~kg} / \mathrm{m}^{2}$ (24.4-30.1) in the coronary bypass group. Body mass index was a significant, but weak, predictor of revascularization, with higher indexes predicting lower rates of coronary bypass. Thirty-day survival did not differ across body mass indexes among treatment groups, but survival curves appeared to separate over longer-term follow-up. An inverted U-shaped survival function was noted across all time points after 30 days, with the lowest risk of death at a body mass index of approximately $26 \mathrm{~kg} / \mathrm{m}^{2}$ (independent of revascularization strategy). Coronary bypass was associated with the highest survival at all later time points, whereas no revascularization was associated with the lowest.
\end{abstract}

Conclusions: Extremes of body mass index are associated with lower long-term survival in patients with significant coronary disease. Revascularization, particularly with coronary bypass, is consistently associated with the best survival across the spectrum of body mass indexes.

The incidence of obesity is increasing rapidly in the developed world, and especially in the United States, where recent estimates of prevalence are over $30 \%$ in adults. ${ }^{1}$ These reports are of great concern from a public health standpoint, given the clear association between high body mass index (BMI) and the risk of death. ${ }^{2-6}$ Furthermore, this relationship does not appear to be linear; instead, the slope of the line increases at BMI over 25, signifying particularly high risk for obese and morbidly obese patients. This negative prognosis is especially true when evaluating cardiovascular mortality outcomes, where relative risks are doubled or even tripled. ${ }^{4,7}$

There has been considerable interest in this problem, but studies to date have been limited by small sample sizes, short duration of follow-up, or methodologic problems, such as arbitrary BMI grouping and failure to account for different coronary artery disease (CAD) treatments. The published

From the Division of Cardiology, Department of Medicine, ${ }^{\mathrm{a}}$ the Duke Clinical Research Institute, ${ }^{b}$ the Division of Thoracic Surgery, ${ }^{c}$ Department of Surgery, Duke University Medical Center, Durham, NC.

Received for publication March 5, 2008; revisions received Oct 30, 2008; accepted for publication Nov 27, 2008.

Address for reprints: Aslan T. Turer, MD, Duke University Medical Center, Box 32197, Durham, NC, 27710 (E-mail: turer001@mc.duke.edu).

J Thorac Cardiovasc Surg 2009; 137:1468-74

$0022-5223 / \$ 36.00$

Copyright (c) 2009 by The American Association for Thoracic Surgery doi:10.1016/j.jtcvs.2008.11.047 data were reviewed in a recent overview that concluded that total and cardiovascular mortality was highest in obese and underweight patients with CAD, confirming the "obesity paradox." ${ }^{8}$ However, the authors were unable to model BMI as a continuous variable because of considerable heterogeneity between cohorts and a lack of patient-level data. Furthermore, no conclusions could be drawn on the relative benefits of one method of CAD management over another for any given BMI. The major outstanding question in clinical practice is whether, given the clear relationship between BMI and outcome, patients and physicians should be altering their revascularization decisions on the basis of the patient's BMI. We used the Duke Databank for Cardiovascular Disease (DDCD) to assess the impact of BMI on the effect of revascularization on survival in patients with significant CAD undergoing coronary angiography.

\section{PATIENTS AND METHODS \\ Patient Population}

This study was approved by the Duke University Institutional Review Board. The population comprised patients undergoing left heart catheterization at Duke University Medical Center between January 1, 1986, and August 31,2004 . Only patients with significant or severe CAD were included in the analysis. Patients were excluded if they had moderate or severe valvular disease, pericardial or congenital heart disease, shock (defined as systolic blood pressure $<80 \mathrm{~mm} \mathrm{Hg}$ or shock as an indication for 

Abbreviations and Acronyms
$\mathrm{BMI}=$ body mass index
$\mathrm{CABG}=$ coronary artery bypass grafting
$\mathrm{CAD}=$ coronary artery disease
DDCD $=$ Duke Databank for Cardiovascular Disease
MI = myocardial infarction
PCI = percutaneous coronary intervention

catheterization), or had previous coronary artery bypass grafting (CABG) surgery. In addition, patients were also excluded if their BMI was less than 18.5 (1 patient) or more than $70 \mathrm{~kg} / \mathrm{m}^{2}$ (12 patients).

Patients were categorized into one of the following three initial revascularization strategy groups on the basis of therapy within 30 days of baseline cardiac catheterization: (1) percutaneous coronary intervention (PCI), if they had PCI; (2) CABG, if they had CABG not preceded by PCI; or (3) no revascularization (NONE), if they did not have revascularization. To minimize potential misclassification of patients who had received prior PCI to the NONE group, we also excluded patients if they had PCI before their baseline catheterization at our center. Patients who died within 5 days of initial catheterization (the median interval between catheterization and CABG at Duke University Medical Center during the study) without receiving PCI or CABG were excluded from NONE. For patients undergoing revascularization, the follow-up was started at the time of the procedure. Once patients were assigned to a revascularization group, all outcome events remained associated with that group, regardless of whether the patient subsequently had revascularization.

\section{Data Collection}

Baseline patient characteristics, medical histories, and physical examinations were collected prospectively before cardiac catheterization and entered into the DDCD. ${ }^{9}$ Angiographic information was summarized to categorize patients into CAD severity groups. Catheterization data were used to define significant CAD as at least one luminal stenosis of $75 \%$ or more and severe $\mathrm{CAD}$ to be either significant 3 -vessel disease or a left main stenosis of $75 \%$ or more.

Patients were contacted at 6 months and 1 year and annually thereafter as part of the DDCD follow-up protocol for collection of vital status, rehospitalization information, subsequent cardiac procedures, and myocardial infarction (MI). Nonresponders to these questionnaires and/or telephone contacts were followed up through the National Death Index for vital status. Deaths were confirmed by an independent mortality committee. As of July 6,2005 , more than $99 \%$ of patients had follow-up. Alive patients were censored at the time of last follow-up.

\section{Statistical Analysis}

Baseline characteristics are categorized into the three revascularization strategy groups and are reported as percentages for discrete variables and as medians with 25th and 75th percentiles for continuous variables. Unadjusted survival results were examined using Kaplan-Meier methods. Survival estimates were generated using Cox proportional hazards regression models.

Baseline variables that were clinically relevant or statistically significant univariable predictors of outcome were selected as candidates for the propensity and final multivariable model. Candidate variables included age, sex, white race, BMI, year of catheterization, systolic and diastolic blood pressure, heart rate, ejection fraction, CAD severity (number of diseased vessels), hypertension, hyperlipidemia, history of heart failure, diabetes mellitus, history of chronic obstructive pulmonary disease, history of cerebrovascular disease, history of MI, history of peripheral vascular disease,

TABLE 1. Baseline characteristics by revascularization strategy

\begin{tabular}{|c|c|c|c|c|}
\hline Variable & Overall $(n=22,877)$ & NONE $(n=7882)$ & PCI $(n=7737)$ & CABG $(n=7258)$ \\
\hline Median age, y (IQR) & $62(53-70)$ & $63(54-70)$ & $59(50-67)$ & $64(56-71)$ \\
\hline Male sex, $\%$ & 68.9 & 66.4 & 67.9 & 72.8 \\
\hline White race, $\%$ & 82.4 & 79.2 & 81.7 & 86.5 \\
\hline BMI, $\mathrm{kg} / \mathrm{m}^{2}$, median (IQR) & $27.2(24.4-30.4)$ & $27.1(24.1-30.3)$ & $27.4(24.8-30.9)$ & $26.9(24.4-30.1)$ \\
\hline History of MI, $\%$ & 55.5 & 52.9 & 63.0 & 50.3 \\
\hline Hypertension, $\%$ & 57.5 & 60.7 & 53.3 & 58.4 \\
\hline Diabetes, $\%$ & 26.1 & 29.4 & 21.6 & 27.2 \\
\hline Hyperlipidemia, \% & 45.2 & 41.9 & 45.7 & 48.3 \\
\hline History of smoking, $\%$ & 64.1 & 64.1 & 65.4 & 62.8 \\
\hline History of cerebrovascular disease, $\%$ & 9.5 & 11.9 & 6.3 & 10.2 \\
\hline History of peripheral vascular disease, $\%$ & 10.7 & 13.5 & 6.4 & 12.2 \\
\hline History of moderate or severe renal disease, $\%$ & 2.4 & 3.2 & 1.9 & 2.0 \\
\hline Congestive heart failure, $\%$ & 17.2 & 25.5 & 9.7 & 16.2 \\
\hline Cath for acute MI, \% & 27.4 & 17.5 & 43.4 & 21.0 \\
\hline Recent MI (6 wk), \% & 42.9 & 35.1 & 57.1 & 36.2 \\
\hline Ejection fraction, $\%$, median (IQR) & $54(43-62)$ & $51(39-61)$ & $56(47-63)$ & $53(43-62)$ \\
\hline \multicolumn{5}{|l|}{ No. of diseased vessels, $\%$} \\
\hline 1 & 39.2 & 48.2 & 59.4 & 8.0 \\
\hline 2 & 29.3 & 27.4 & 31.3 & 29.1 \\
\hline 3 & 31.5 & 24.4 & 9.4 & 62.9 \\
\hline \multicolumn{5}{|l|}{ Extent of CAD, \% } \\
\hline Significant (not severe) & 67.0 & 75.0 & 90.2 & 33.7 \\
\hline Severe & 33.0 & 25.0 & 9.8 & 66.3 \\
\hline
\end{tabular}

$B M I$, Body mass index; $C A B G$, coronary artery bypass grafting; $C A D$, coronary artery disease; $I Q R$, interquartile range; $M I$, myocardial infarction; $N O N E$, no revascularization; $P C I$, percutaneous coronary intervention. All $P<.001$, except for smoking $(P=.003)$. 


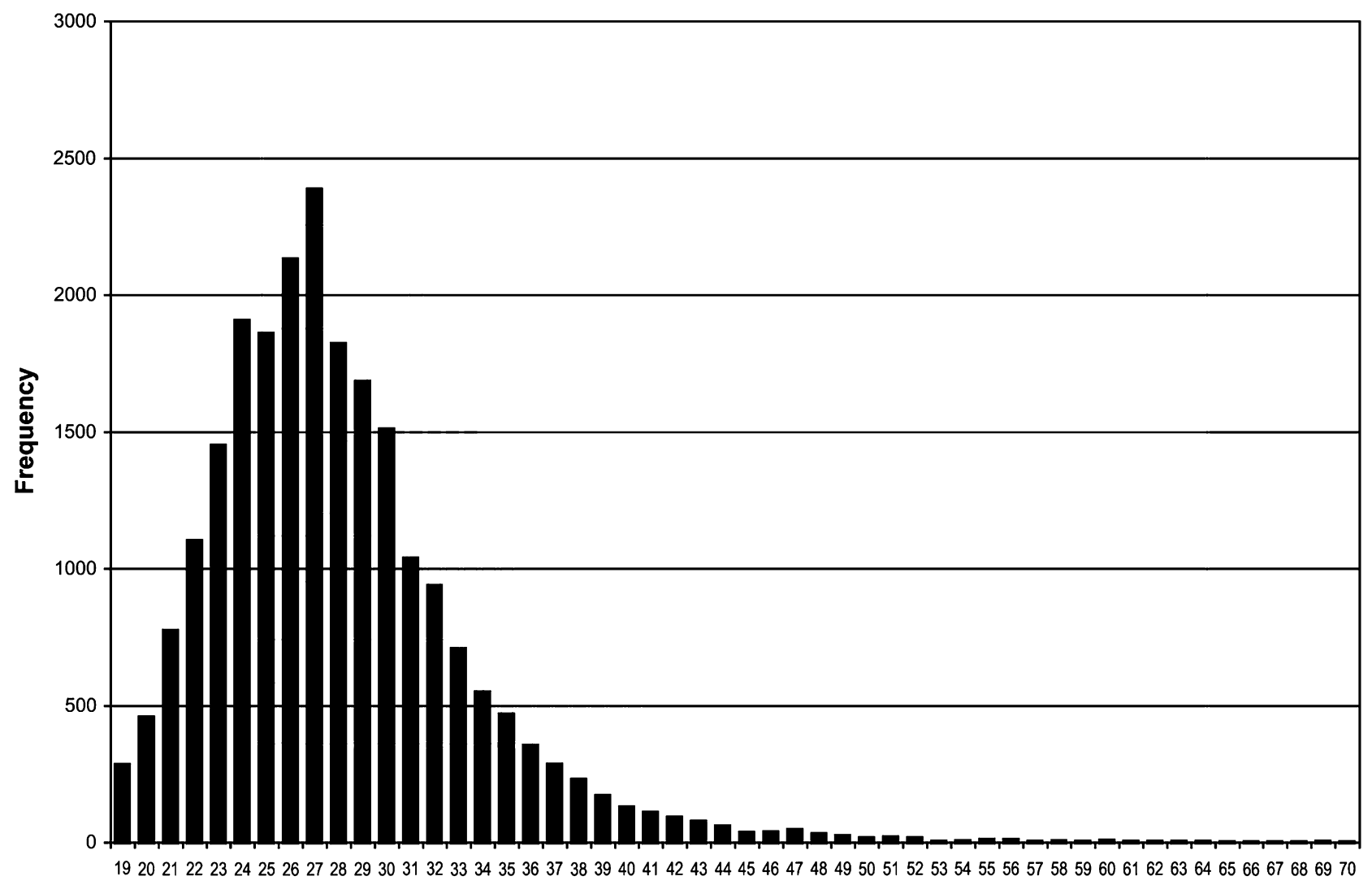

BMI (rounded to whole numbers)

FIGURE 1. BMI distribution of the study population. BMI, Body mass index.

family history of CAD, history of liver disease, history of moderate or severe kidney disease, connective tissue disease, history of dementia, history of metastatic cancer, history of any tumor, history of peptic ulcer, mitral insufficiency, New York Heart Association Class, MI within prior 6 weeks, third heart sound, carotid bruits, acute MI, mild valvular disease, history of smoking, left main disease of $50 \%$ or more, elective catheterization, and urgent catheterization.

Logistic regression analysis was used to determine the probability of the physician's and patient's propensity to choose a specific revascularization strategy. Three propensity scores-(1) CABG versus NONE, (2) CABG versus PCI, and (3) PCI versus NONE-were created for each patient, which, taken as a whole, represent that patient's probability of selection for each strategy relative to another. Propensity scores were included in the final models.

For the final multivariable models, variables were chosen using stepwise selection with a $P$ value of .05 as the level of statistical significance. Interactions of revascularization strategy with CAD severity, BMI with CAD severity, and BMI with revascularization strategy were tested for significance. ${ }^{10}$ Splines were used to generate curves comparing survival across BMI. ${ }^{11}$ All analyses were performed with SAS software version 8.2 (SAS Institute Inc, Cary, NC).

\section{RESULTS}

The analysis included 22,877 patients with significant or severe CAD. The median duration of follow-up was 7 years (interquartile range $3.1-11.9$ years). Approximately $65 \%$ of the patients in the cohort were either followed up for over 10 years or had died within 10 years of follow-up.
The baseline characteristics stratified by revascularization strategy are shown in Table 1. The median BMI was $27.2 \mathrm{~kg} /$ $\mathrm{m}^{2}\left(24.4-30.4 \mathrm{~kg} / \mathrm{m}^{2}\right)$ in the overall cohort, $27.1 \mathrm{~kg} / \mathrm{m}^{2}$ $\left(24.1-30.3 \mathrm{~kg} / \mathrm{m}^{2}\right)$ in the NONE group, $27.4 \mathrm{~kg} / \mathrm{m}^{2}(24.8-$ $\left.30.9 \mathrm{~kg} / \mathrm{m}^{2}\right)$ in the PCI group, and $26.9 \mathrm{~kg} / \mathrm{m}^{2}(24.4-30.1$ $\mathrm{kg} / \mathrm{m}^{2}$ ) in the CABG group. The BMI distribution of the entire study population is shown in Figure 1. When examined by revascularization strategy, there were no major differences in the distribution of BMIs.

Table 2 shows unadjusted survivals. The adjusted survivals of the study population stratified by revascularization strategy are shown in Figure 2. CABG was associated with higher adjusted survival than the other treatment modalities

TABLE 2. Unadjusted survivals by revascularization strategy

\begin{tabular}{lccc}
\hline Time & NONE & PCI & CABG \\
\hline $30 \mathrm{~d}$ & $97 \%$ & $98 \%$ & $97 \%$ \\
$6 \mathrm{mo}$ & $93 \%$ & $97 \%$ & $95 \%$ \\
$1 \mathrm{y}$ & $90 \%$ & $96 \%$ & $94 \%$ \\
$5 \mathrm{y}$ & $70 \%$ & $87 \%$ & $82 \%$ \\
$10 \mathrm{y}$ & $51 \%$ & $73 \%$ & $62 \%$ \\
$15 \mathrm{y}$ & $36 \%$ & $53 \%$ & $42 \%$ \\
\hline \multicolumn{2}{l}{$C A B G$, Coronary artery bypass grafting; $N O N E$, no revascularization; $P C I$, percutane- }
\end{tabular}

ous coronary intervention. 


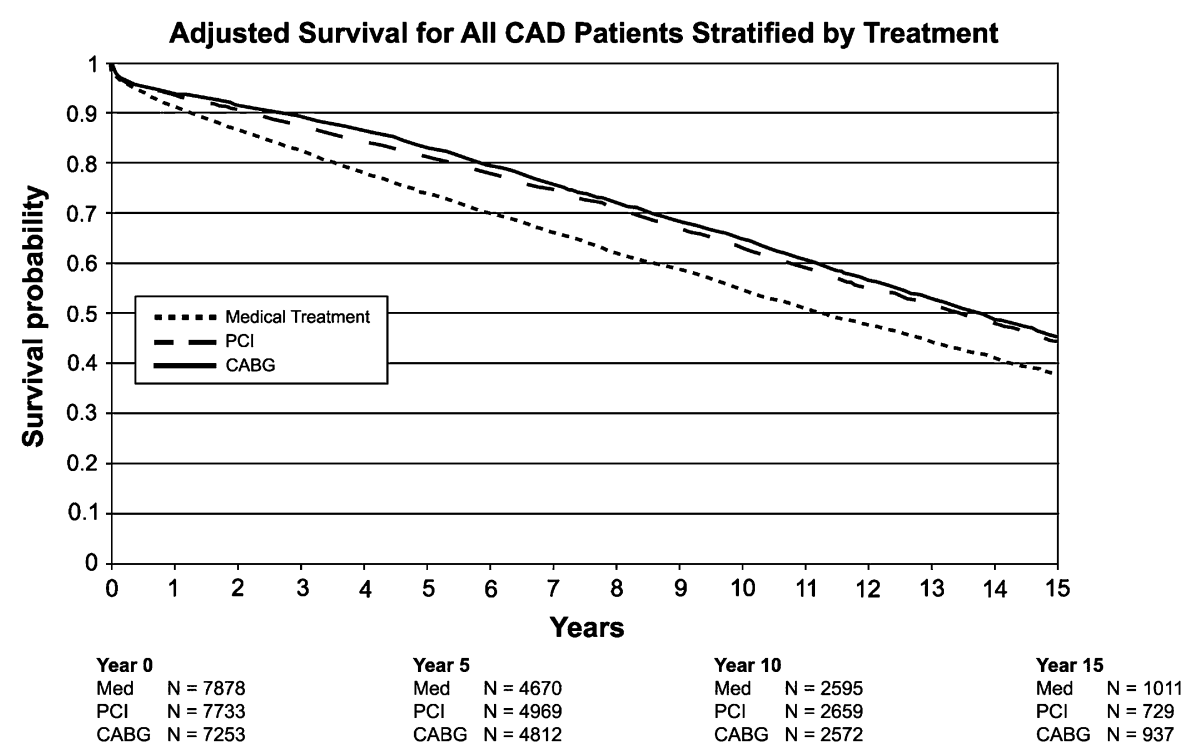

FIGURE 2. Adjusted survival for all patients stratified by revascularization strategy. $C A D$, Coronary artery disease; $C A B G$, coronary artery bypass graft; $P C I$, percutaneous coronary intervention.

after 12 months, and this benefit appeared to be consistent over the duration of follow-up. Table 3 shows the predictors of revascularization strategy based on the results of the logistic regression propensity models. BMI was a significant variable in each of the propensity scores, although its relative contribution to the overall probability of undergoing a particular procedure was small compared with other clinical variables. The majority of patients were treated with a single revascularization strategy. Crossover rates were $11.9 \%$ for NONE to PCI, $13.8 \%$ for CABG to PCI, $21 \%$ for NONE to $\mathrm{CABG}$, and $21 \%$ for PCI to CABG. The median time to crossover from NONE to CABG was 3 years and from PCI to CABG, 1.5 years.

Survival estimates for the different revascularization strategy groups at 30 days, 1 year, and 10 years are provided in Figure 3. There was no significant difference in survival at 30 days among revascularization strategy groups or across BMI. At longer follow-up, the survival curves continued to diverge, with $C A B G$ being associated with the highest survival across the entire spectrum of BMI. NONE was consistently associated with the lowest long-term survival. This relationship was similar when analyzed for procedures performed in the early balloon angioplasty (1986-1990), late balloon angioplasty (1991-1995), and stent (1996-2004) eras (data not shown). The BMI inflection point of these survival curves was at a BMI of approximately $26 \mathrm{~kg} / \mathrm{m}^{2}$ and was independent of revascularization strategy (interaction $P$ value $=.12$ ) .

Among the entire cohort, there were $711(3.1 \%)$ patients with morbid obesity (BMI $\geq 40$ ). Of these, $32.3 \%$ were treated with NONE, $43.2 \%$ with PCI, and $24.5 \%$ received CABG. The revascularization rate was not different in pa- tients with BMIs of 40 or more compared with those with BMIs less than 40 (67.7 vs $65.5 \% ; P=.245$ ); however, there was less use of CABG (24.5 vs $32.0 \% ; P<.0001)$. Among patients with severe (ie, left main or 3-vessel) CAD, there was a trend toward a lower rate of CABG in morbidly obese patients compared with those not morbidly obese (55.3 vs $61.5 \% ; P=.072)$.

\section{DISCUSSION}

Although there is a clear and previously described excess risk associated with extremes of BMI, the association between revascularization strategy and better outcome appears to be independent of BMI in this large cohort of patients with CAD undergoing coronary angiography. Importantly, revascularization (especially with $\mathrm{CABG}$ ) is associated with a higher rate of survival even at the extremes of BMI.

Prior work has described a similar U-shaped relationship between BMI and the risk of overall and cardiovascular death. ${ }^{4,8}$ Our data support these findings of an "obesity paradox"; however, this is the first analysis to include the impact of treatment strategy in such a way as to allow a direct comparison of outcomes between patients treated with revascularization strategies for any given BMI.

At one extreme, very low BMI has been associated with overall mortality, possibly through a confounding effect by unrecognized or unmeasured comorbidities. ${ }^{4,8}$ At the other extreme, obesity continues to attract attention as its prevalence increases. It is clearly linked to several major cardiovascular risk factors but is also increasingly recognized as an independent contributor both to the development of CAD and to cardiovascular death. ${ }^{8,12-14}$ The results of this analysis show that BMI influences the risk of death even 
TABLE 3. Major predictors of each revascularization strategy from the propensity model

\begin{tabular}{|c|c|c|c|c|}
\hline Variable & Wald $\chi^{2}$ & OR & \multicolumn{2}{|c|}{$95 \% \mathrm{CI}$} \\
\hline \multicolumn{5}{|c|}{ A. PCI vs NONE: Probability of undergoing PCI } \\
\hline Year of catheterization* & 679.9 & & & \\
\hline $1986-1993$ & & 1.201 & 1.181 & 1.222 \\
\hline 1997-2004 & & 1.097 & 1.070 & 1.125 \\
\hline Ejection fraction (per $1 \%$ increase) & 256.9 & 1.037 & 1.032 & 1.041 \\
\hline Acute MI & 165.8 & 2.226 & 1.970 & 2.514 \\
\hline Left main disease $\geq 50 \%$ & 140.4 & 0.384 & 0.328 & 0.450 \\
\hline MI within prior $6 \mathrm{wk}$ & 103.3 & 2.097 & 1.818 & 2.418 \\
\hline No. of diseased vessels & 102.8 & 0.769 & 0.731 & 0.809 \\
\hline NYHA class (classes I-III vs class IV) & 94.1 & 0.645 & 0.591 & 0.705 \\
\hline Elective catheterization & 70.8 & 0.677 & 0.618 & 0.741 \\
\hline History of MI & 48.6 & 0.635 & 0.559 & 0.721 \\
\hline White race & 32.3 & 1.317 & 1.198 & 1.448 \\
\hline Age (per 10-y increase) & 31.8 & 0.908 & 0.878 & 0.939 \\
\hline History of peripheral vascular disease & 27.9 & 0.707 & 0.622 & 0.804 \\
\hline History of cerebrovascular disease & 20.6 & 0.737 & 0.646 & 0.841 \\
\hline Mild valvular disease & 14.3 & 0.522 & 0.373 & 0.731 \\
\hline BMI (below 26 , or per $1 \mathrm{~kg} / \mathrm{m}^{2}$ increase) & 11.4 & 1.038 & 1.016 & 1.061 \\
\hline Hyperlipidemia & 10.4 & 1.131 & 1.050 & 1.219 \\
\hline Diabetes mellitus & 10.3 & 0.868 & 0.796 & 0.946 \\
\hline \multicolumn{5}{|c|}{ B. CABG vs NONE: Probability of undergoing CABG } \\
\hline No. of diseased vessels & 2643.7 & 4.126 & 3.909 & 4.355 \\
\hline Left main disease $\geq 50 \%$ & 245.7 & 2.282 & 2.059 & 2.530 \\
\hline Ejection fraction & 222.2 & 1.047 & 1.041 & 1.054 \\
\hline Age (OR per $10 \mathrm{y})$ & 164.4 & & & \\
\hline Below 67 y & & 1.115 & 1.055 & 1.178 \\
\hline Above $67 \mathrm{y}$ & & 0.513 & 0.462 & 0.568 \\
\hline Elective catheterization & 113.3 & 0.624 & 0.572 & 0.680 \\
\hline White race & 98.7 & 1.721 & 1.546 & 1.915 \\
\hline Year of catheterization* & 76.5 & 1.039 & 1.030 & 1.048 \\
\hline NYHA class & 72.6 & 0.841 & 0.808 & 0.875 \\
\hline History of cerebrovascular disease & 30.2 & 0.704 & 0.621 & 0.798 \\
\hline Diabetes mellitus & 29.2 & 0.779 & 0.712 & 0.853 \\
\hline History of MI & 27.6 & 0.734 & 0.654 & 0.824 \\
\hline Mild valvular disease & 23.7 & 0.469 & 0.346 & 0.636 \\
\hline Hyperlipidemia & 23.1 & 1.215 & 1.122 & 1.315 \\
\hline History of peripheral vascular disease & 21.7 & 0.757 & 0.673 & 0.851 \\
\hline Hypertension & 14.8 & 0.851 & 0.784 & 0.924 \\
\hline $\begin{array}{l}\text { History of moderate or severe renal } \\
\text { disease }\end{array}$ & 14.1 & 0.622 & 0.486 & 0.797 \\
\hline BMI & 13.9 & & & \\
\hline Below 26 & & 1.030 & 1.006 & 1.056 \\
\hline Above 26 & & 0.982 & 0.972 & 0.992 \\
\hline History of connective tissue disease & 10.1 & 0.389 & 0.217 & 0.697 \\
\hline \multicolumn{5}{|c|}{ C. CABG vs PCI: Probability of undergoing CABG } \\
\hline No. of diseased vessels & 3264.0 & 6.330 & 5.941 & 6.743 \\
\hline Left main disease $\geq 50 \%$ & 525.9 & 6.283 & 5.370 & 7.352 \\
\hline Year of catheterization* & 164.3 & & & \\
\hline $1986-1993$ & & 0.890 & 0.871 & 0.909 \\
\hline 1997-2004 & & 0.960 & 0.933 & 0.989 \\
\hline Acute MI & 101.8 & 0.450 & 0.386 & 0.526 \\
\hline MI within $6 \mathrm{wk}$ before catheterization & 41.1 & 0.648 & 0.568 & 0.740 \\
\hline $\begin{array}{l}\text { Ejection fraction (below } 60 \text {, or per } 1 \% \\
\text { increase) }\end{array}$ & 32.4 & 0.987 & 0.983 & 0.992 \\
\hline
\end{tabular}

TABLE 3. Continued

\begin{tabular}{lrrrr}
\hline \multicolumn{1}{c}{ Variable } & Wald $\chi^{2}$ & OR & 95\% CI \\
\hline Age $($ or per 10 y) & 29.3 & & \\
Below 70 y & & 1.143 & 1.083 & 1.206 \\
Above 70 y & 0.699 & 0.591 & 0.826 \\
BMI & 14.3 & 0.984 & 0.975 & 0.992 \\
White race & 13.4 & 1.260 & 1.113 & 1.427 \\
\hline$B M I$, Body mass index; $C A B G$, coronary artery bypass grafting; $C I$, confidence inter- \\
val; $M I$, myocardial infarction; $N Y H A$, New York Heart Association; $N O N E$, no revas- \\
cularization; $O R$, odds ratio; $P C I$, percutaneous coronary intervention. *Odds ratio for \\
year of catheterization refers to the yearly increase in odds of receiving one treatment \\
over another; for PCI vs. NONE and CABG vs. PCI, the OR from 1994-1996 did not \\
increase and was the same as 1993 . Only Wald $\chi^{2}$ values over 10 are shown.
\end{tabular}

after revascularization and medical therapy for CAD, and, furthermore, that it affects prognosis independently of revascularization strategy.

The precise reason for the excess risk associated with obesity is unclear, but a number of biological mechanisms have been postulated, including effects on vascular remodeling ${ }^{15}$ and endothelial function, ${ }^{16}$ associated low-level chronic inflammation, ${ }^{17}$ impaired ventricular function, ${ }^{18}$ left ventricular hypertrophy, ${ }^{19}$ and QT prolongation. ${ }^{20}$ Confounding from low cardiorespiratory fitness, itself probably a significant predictor of adverse cardiovascular outcomes, may also, in part, explain the influence of BMI on prognosis. ${ }^{21-23}$

Finally, biases and barriers may exist in access to medical care for the obese and especially the morbidly obese patient, which may contribute negatively to outcomes. ${ }^{24}$ The results of propensity modeling suggest that BMI does influence the likelihood of coronary revascularization and, perhaps more important, the mode of revascularization selected. This idea of a potential treatment bias is further supported by the finding that, even among patients with traditionally "surgical" disease (namely, left main or 3-vessel disease), rates of $\mathrm{CABG}$ were lower in those patients who were morbidly obese.

It is commonly believed that obese patients may not be appropriate surgical candidates because of an increased risk of complications $^{25-36}$ and higher mortality after CABG. There are data, including from this analysis, to support the finding that obese patients undergoing CABG have worse outcomes than nonobese patients, ${ }^{8,31,35-39}$ although a number of previous studies conversely have not found higher mortality with CABG in obese $25-30,32-34,40-45$ and severely obese patients. ${ }^{25,28,32,40,41,44,46}$ All of these studies, however, have failed to account for the outcomes of similar patients treated with PCI or without revascularization. Although obese patients treated with CABG may have worse outcomes than lighter-weight patients, their outcomes are better with CABG than with alternative revascularization strategies or medical therapy.

Several limitations of our study must be acknowledged. First, this is a single-center study and may not reflect the experiences of other institutions. For example, the high 

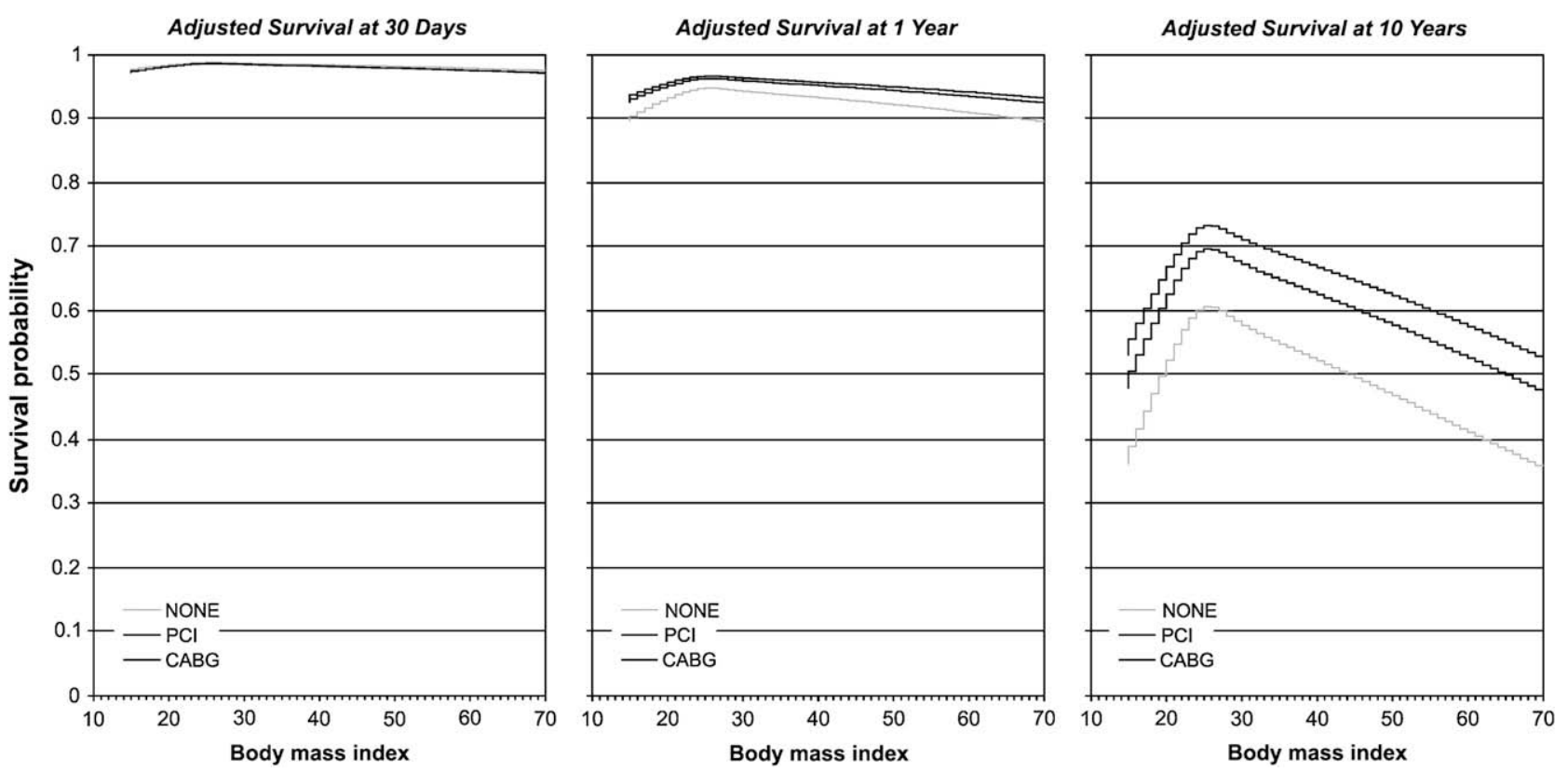

FIGURE 3. Survival across the spectrum of BMI by treatment group at short-, intermediate-, and long-term follow-up. $C A B G$, Coronary artery bypass grafting; $P C I$, percutaneous coronary intervention.

rate of smoking in our population may reflect local social factors. Second, the DDCD includes patients enrolled over approximately 20 years. Although this provides for a large population and a long duration of follow-up, there have been therapeutic advancements in the treatment of CAD from both a medical and revascularization standpoint, and findings from the past may be less relevant to the future. The DDCD does not contain longitudinal information on medication use, so we cannot account for the adequacy of medical therapy with any revascularization strategy. As with any observational analysis, there may be measured or unmeasured confounders that are associated with either revascularization strategy or outcome. Patients with acute MI were more likely to have PCI and those with multivessel disease were more likely to receive CABG. We performed propensity analysis to adjust for the likelihood of receiving a particular treatment and to mitigate the effects of measurable confounders. There may also be unmeasured confounders, such as socioeconomic and psychologicl factors, which are not collected and thus cannot be adjusted for. Although observational databases have limitations, because patients of extremes of BMI are often excluded from randomized clinical trials, large observational datasets have an important role to play in understanding the influence of BMI on outcome in real world clinical practice. Finally, we did not assess the impact of revascularization beyond 30 days-such as repeat revascularization, crossover from medical to revascularization, or weight loss. Only a minority of the population crossed over, and there are considerable analytic challenges in accounting for crossover, in modeling time- to-crossover, and introducing bias from patients dying before crossover.

In conclusion, although extremes of BMI are associated with worse survival in patients with CAD undergoing angiography, revascularization (particularly with $\mathrm{CABG}$ ) is associated with better outcomes across all BMIs. Obese patients with significant $\mathrm{CAD}$ amenable to surgical revascularization should be considered for CABG.

\section{References}

1. Ogden CL, Carroll MD, Curtin LR, McDowell MA, Tabak CJ, Flegal KM. Prevalence of overweight and obesity in the United States, 1999-2004. JAMA. 2006; 295:1549-55.

2. Lahmann PH, Lissner L, Gullberg B, Berglund G. A prospective study of adiposity and all-cause mortality: the Malmo Diet and Cancer Study. Obes Res. 2002;10: 361-9.

3. Flegal KM, Graubard BI, Williamson DF, Gail MH. Excess deaths associated with underweight, overweight, and obesity. JAMA. 2005;293:1861-7.

4. Calle EE, Thun MJ, Petrelli JM, Rodriguez C, Heath CW Jr. Body-mass index and mortality in a prospective cohort of U.S. adults. $N$ Engl J Med. 1999;341: 1097-105.

5. Singh PN, Lindsted KD, Fraser GE. Body weight and mortality among adults who never smoked. Am J Epidemiol. 1999;150:1152-64.

6. Garrison RJ, Castelli WP. Weight and thirty-year mortality of men in the Framingham Study. Ann Intern Med. 1985;103:1006-9.

7. Seidell JC, Verschuren WM, van Leer EM, Kromhout D. Overweight, underweight, and mortality. A prospective study of 48,287 men and women. Arch Intern Med. 1996;156:958-63.

8. Romero-Corral A, Montori VM, Somers VK, Korinek J, Thomas RJ, Allison TG et al. Association of body weight with total mortality and with cardiovascular events in coronary artery disease: a systematic review of cohort studies. Lancet. 2006;368:666-78.

9. Califf RM, Harrell FE Jr, Lee KL, Rankin JS, Hlatky MA, Mark DB, et al. The evolution of medical and surgical therapy for coronary artery disease. A 15year perspective. JAMA. 1989;261:2077-86.

10. Smith PK, Califf RM, Tuttle RH, Shaw LK, Lee KL, Delong ER, et al. Selection of surgical or percutaneous coronary intervention provides differential longevity benefit. Ann Thorac Surg. 2006;82:1420-8. 
11. Stone CJ, Koo C. Additive splines in statistics. In: Proceedings of the Statistical Computing Section. Alexandria (VA): American Statistical Association; 1985. p. 45-8.

12. Mora S, Yanek LR, Moy TF, Fallin MD, Becker LC, Becker DM. Interaction of body mass index and Framingham risk score in predicting incident coronary disease in families. Circulation. 2005;111:1871-6.

13. Cassidy AE, Bielak LF, Zhou Y, Sheedy PF 2nd, Turner ST, Breen JF, et al. Progression of subclinical coronary atherosclerosis: does obesity make a difference? Circulation. 2005;111:1877-82.

14. Eckel RH, Krauss RM. American Heart Association call to action: obesity as a major risk factor for coronary heart disease. AHA Nutrition Committee. Circulation. 1998;97:2099-100.

15. Al Suwaidi J, Higano ST, Hamasaki S, Holmes DR, Lerman A. Association between obesity and coronary atherosclerosis and vascular remodeling. Am J Cardiol. 2001;88:1300-3.

16. Al Suwaidi J, Higano ST, Holmes DR Jr, Lennon R, Lerman A. Obesity is independently associated with coronary endothelial dysfunction in patients with normal or mildly diseased coronary arteries. J Am Coll Cardiol. 2001;37:1523-8.

17. Yudkin JS, Stehouwer CD, Emeis JJ, Coppack SW. C-reactive protein in healthy subjects: associations with obesity, insulin resistance, and endothelial dysfunction-a potential role for cytokines originating from adipose tissue? Arterioscler Thromb Vasc Biol. 1999;19:972-8.

18. de Divitiis O, Fazio S, Petitto M, Maddalena G, Contaldo F, Mancini M. Obesity and cardiac function. Circulation. 1981;64:477-82.

19. Savage DD, Levy D, Dannenberg AL, Garrison RJ, Castelli WP. Association of echocardiographic left ventricular mass with body size, blood pressure and physical activity (the Framingham Study). Am J Cardiol. 1990;65:371-6.

20. Pontiroli AE, Pizzocri P, Saibene A, Girola A, Koprivec D, Fragasso G. Left ventricular hypertrophy and QT interval in obesity and in hypertension: effects of weight loss and of normalisation of blood pressure. Int J Obes Relat Metab Disord. 2004;28:1118-23.

21. Crespo CJ, Palmieri MR, Perdomo RP, Mcgee DL, Smit E, Sempos CT, et al. The relationship of physical activity and body weight with all-cause mortality: results from the Puerto Rico Heart Health Program. Ann Epidemiol. 2002;12:543-52.

22. Lee CD, Blair SN, Jackson AS. Cardiorespiratory fitness, body composition, and all-cause and cardiovascular disease mortality in men. Am J Clin Nutr. 1999;69: 373-80.

23. Wei M, Kampert JB, Barlow CE, Nichaman MZ, Gibbons LW, Paffenbarger RS Jr, et al. Relationship between low cardiorespiratory fitness and mortality in normalweight, overweight, and obese men. JAMA. 1999;282:1547-53.

24. Yancy WS Jr, Olsen MK, Curtis LH, Schulman KA, Cuffe MS, Oddone EZ. Variations in coronary procedure utilization depending on body mass index. Arch Intern Med. 2005;165:1381-7.

25. Birkmeyer NJ, Charlesworth DC, Hernandez F, Leavitt BJ, Marrin CA, Morton JR, et al. Obesity and risk of adverse outcomes associated with coronary artery bypass surgery. Northern New England Cardiovascular Disease Study Group. Circulation. 1998;97:1689-94.

26. Engelman DT, Adams DH, Byrne JG, Aranki SF, Collins JJ Jr, Couper GS, et al. Impact of body mass index and albumin on morbidity and mortality after cardiac surgery. J Thorac Cardiovasc Surg. 1999;118:866-73.

27. Fasol R, Schindler M, Schumacher B, Schlaudraff K, Hannes W, Seitelberger R, et al. The influence of obesity on perioperative morbidity: retrospective study of 502 aortocoronary bypass operations. Thorac Cardiovasc Surg. 1992;40:126-9.

28. Gadaleta D, Risucci DA, Nelson RL, Tortolani AJ, Hall M, Parnell V, et al. Effects of morbid obesity and diabetes mellitus on risk of coronary artery bypass grafting. Am J Cardiol. 1992;70:1613-4.
29. Kim J, Hammar N, Jakobsson K, Luepker RV, McGovern PG, Ivert T. Obesity and the risk of early and late mortality after coronary artery bypass graft surgery. Am Heart J. 2003;146:555-60.

30. Koshal A, Hendry P, Raman SV, Keon WJ. Should obese patients not undergo coronary artery surgery? Can J Surg. 1985;28:331-4.

31. Kurki TS, Kataja M. Preoperative prediction of postoperative morbidity in coronary artery bypass grafting. Ann Thorac Surg. 1996;61:1740-5.

32. Moulton MJ, Creswell LL, Mackey ME, Cox JL, Rosenbloom M. Obesity is not a risk factor for significant adverse outcomes after cardiac surgery. Circulation. 1996;94(9 Suppl):II87-92.

33. Prasad US, Walker WS, Sang CT, Campanella C, Cameron EW. Influence of obesity on the early and long term results of surgery for coronary artery disease. Eur J Cardiothorac Surg. 1991;5:67-72; discussion 72-3.

34. Ranucci M, Cazzaniga A, Soro G, Morricone L, Enrini R, Caviezel F. Obesity and coronary artery surgery. J Cardiothorac Vasc Anesth. 1999;13:280-4.

35. Schwann TA, Habib RH, Zacharias A, Parenteau GL, Riordan CJ, Durham SJ, et al. Effects of body size on operative, intermediate, and long-term outcomes after coronary artery bypass operation. Ann Thorac Surg. 2001;71:521-30; discussion 530-1.

36. Habib RH, Zacharias A, Schwann TA, Riordan CJ, Durham SJ, Shah A. Effects of obesity and small body size on operative and long-term outcomes of coronary artery bypass surgery: a propensity-matched analysis. Ann Thorac Surg. 2005;79: 1976-86.

37. Gurm HS, Whitlow PL, Kip KE: BARI Investigators. The impact of body mass index on short- and long-term outcomes in patients undergoing coronary revascularization. Insights from the bypass angioplasty revascularization investigation (BARI). J Am Coll Cardiol. 2002;39:834-40.

38. Sprecher DL, Pearce GL. How deadly is the "deadly quartet'? A post-CABG evaluation. J Am Coll Cardiol. 2000;36:1159-65.

39. Prabhakar G, Haan CK, Peterson ED, Coombs LP, Cruzzavala JL, Murray GF. The risks of moderate and extreme obesity for coronary artery bypass grafting outcomes: a study from the Society of Thoracic Surgeons' database. Ann Thorac Surg. 2002;74:1125-30; discussion 1130-1.

40. Jin R, Grunkemeier GL, Furnary AP, Handy JR Jr. Is obesity a risk factor for mortality in coronary artery bypass surgery? Circulation. 2005;111:3359-65.

41. Kuduvalli M, Grayson AD, Oo AY, Fabri BM, Rashid A. Risk of morbidity and in-hospital mortality in obese patients undergoing coronary artery bypass surgery. Eur J Cardiothorac Surg. 2002;22:787-93.

42. Brandt M, Harder K, Walluscheck KP, Schöttler J, Rahimi A, Möller F, et al. Severe obesity does not adversely affect perioperative mortality and morbidity in coronary artery bypass surgery. Eur $J$ Cardiothorac Surg. 2001; 19:662-6.

43. Christakis GT, Weisel RD, Buth KJ, Fremes SE, Rao V, Panagiotopoulos KP, et al. Is body size the cause for poor outcomes of coronary artery bypass operations in women? J Thorac Cardiovasc Surg. 1995;110:1344-56; discussion 1356-8.

44. Clough RA, Leavitt BJ, Morton JR, Plume SK, Hernandez F, Nugent W, et al. The effect of comorbid illness on mortality outcomes in cardiac surgery. Arch Surg. 2002; 137:428-32; discussion 432-3.

45. Herlitz J, Brandrup-Wognsen G, Karlsson T, Karlson B, Haglid M, Sjöland H. Predictors of death and other cardiac events within 2 years after coronary artery bypass grafting. Cardiology. 1998;90:110-4.

46. Rohs T Jr, Polanski P, Just SC, Gordon W, Just-Viera JO. Early complications and long-term survival in severely obese coronary bypass patients. Am Surg. 1995;61: 949-53. 